\title{
Synthesis of Mn Zn Ferrites by Oxide and Wet Chemical Methods
}

\author{
Vikas J. Pissurlekar \\ Department of Chemistry, P.E.S.'s .R.S.N College of Arts and Science, Ponda, Goa. - 403401
}

\begin{abstract}
Mn Zn ferrite nanoparticles have been synthesized by taking two different starting chemical compounds, oxides as solid material and metal salts in solution by precursor method using hydrazine oxalate ligand by auto combustion self-decomposition technique. The ferrites obtained from oxides and the metal salts were separately studied for their crystallite size, microstructure and magnetic properties using X-ray diffraction (XRD), scanning electron microscopy (SEM) and pulse field magnetic hysteresis loop tracer methods. The results showed that single phase ferrite could be achieved directly without any post calcinations. However, the crystallite size of the oxide auto combusted sample (24nm) was finer than that of the wet chemical method (43nm).The wet chemical synthesized Mn Zn ferrite with the larger crystallite size exhibited the larger magnetization of $53.4 \mathrm{emu} / \mathrm{g}$ than that of 39.6 emu/g for the oxide nanoparticles.
\end{abstract}

Keywords: oxides, metal salts, self-decomposition, microstructure, magnetic properties

\section{Introduction}

Magnetic nanoparticles of spinel ferrites are the most widely used. The applications of these versatile ceramic compounds range from magnetic recording, transformers, transmission devices, biomedical applications [1, 4] Mn-Zn ferrites with a spinel structure constitute an important group of soft magnetic ferrite [5]. The behavior of ferrites in the magnetic field is associated with the content and distribution of magnetic $\left(\mathrm{Mn}^{2+}, \mathrm{Fe}^{2+}, \mathrm{Fe}^{3+}\right)$ and nonmagnetic $\left(\mathrm{Zn}^{2+}\right)$ ions in the octahedral and tetrahedral sites in the crystal lattice, which, in turn, depend on the synthesis method and other conditions [6, 7] .Mn $\mathrm{Zn}$ ferrite has properties like high saturation magnetization, high magnetic permeability, high electrical resistance, and also biocompatibility [8]. It is important to have precise control of chemical composition and particle size distribution for the preparation of high quality $\mathrm{Mn}-\mathrm{Zn}$ ferrite materials [9, 10]. Traditionally large scale commercial production of $\mathrm{Mn}-\mathrm{Zn}$ ferrite powders are usually obtained by ceramic method involving solid phase reactions at high temperatures. The main disadvantages of the technique are the inhomogeneities in chemistry and phase composition as well as of wide particle size distributions. Many novel wet-chemical methods are developed in recent years, including co precipitation, precursor, hydrothermal, sol-gel $[11,14]$. In the present work, two different starting methods are tried to overcome the disadvantages of the ceramic method. In the first method solid oxides are ball milled and then treated with a ligand to form a precursor which is auto-combusted to obtain the ferrite materials. In second method metal salts solution is obtained and treated with same ligand and auto-combusted to synthesize the ferrites. The microstructure and magnetic properties of the Mn $\mathrm{Zn}$ ferrite synthesized by these two techniques which are similar with respect to the occurrence of a self-propagating reaction upon ignition were compared and studied.

\section{Experimental Details}

In the present paper two different methods have been used to prepare manganese zinc ferrite with different starting materials.

a) Synthesis of $\mathrm{Mn}_{0.6} \mathrm{Zn}_{0.4} \mathrm{Fe}_{2} \mathrm{O}_{4}$ ferrites by oxide method: In a typical experiment, a mixture of $\mathrm{MnO}_{2}, \mathrm{ZnO}$ and $\mathrm{Fe}_{2} \mathrm{O}_{3}$ in stoichiometric amount was ball milled for 10 hours at 80 rpm speed. It was then treated with aqueous oxalate hydrazinate ligand to a thick paste. Further the paste was dried on a burner using silica crucible. On drying it got ignited and undergoes auto combustion self- decomposition into the powder. This powder was used for characterization and study of structural, electrical and magnetic properties

b) Synthesis of $\mathrm{Mn}_{0.6} \mathrm{Zn}_{0.4} \mathrm{Fe}_{2} \mathrm{O}_{4}$ ferrites by wet chemical method:

In a typical experiment calculated, amount of $\mathrm{Ni}\left(\mathrm{NO}_{3}\right)_{2} \cdot 6 \mathrm{H}_{2} \mathrm{O}, \mathrm{Zn}\left(\mathrm{NO}_{3}\right)_{2} .6 \mathrm{H}_{2} \mathrm{O}$ and $\mathrm{Fe}\left(\mathrm{NO}_{3}\right)_{3} .9 \mathrm{H}_{2} \mathrm{O}$ were dissolved in minimum quantity of distilled water. It was then treated with aqueous oxalate hydrazinate ligand. The mixture was then kept for drying on a hot plate in a silica crucible, on drying it gets ignited and underwent auto combustion self- decomposition to give the product. The powder obtained was characterized by different analytical techniques and was studied for structural, electrical and magnetic properties.

The crystalline phases were investigated of the prepared Mn - Zn ferrite nanoparticles by means of X-ray powder diffraction using Rigaku, X-ray advance Power diffractometer using $\mathrm{Cu} \mathrm{K \alpha}$ radiation $(\lambda=1 \cdot 54 \AA)$.. The chemical vibrational mode of ferrite samples was studied by Fourier transform infrared spectroscopy (FTIR) recorded with Shimadzu Model IR prestige 21 series spectrophotometer. The average particle size $\mathrm{T}$ was calculated using most intense peak (311) employing the Scherer formula. The particle size and morphology studies were carried out using Scanning Electron Microscope (SEM) Model JEOL 5800LV. The saturation magnetization measurements of all the samples were carried out at room 


\section{International Journal of Science and Research (IJSR) \\ ISSN (Online): 2319-7064 \\ Index Copernicus Value (2013): 6.14 | Impact Factor (2014): 5.611}

temperature using Pulse Field Magnetic Hysteresis Loop Tracer, supplied by Magneta India Model PFMHT-1. Magnetization, coercivity and remanence magnetization were calculated from the hysteresis loops. The Curie temperature was determined by using Dual Channel Data Acquisition System supplied by Magneta India Model pfm2.

\section{Results and Discussion}

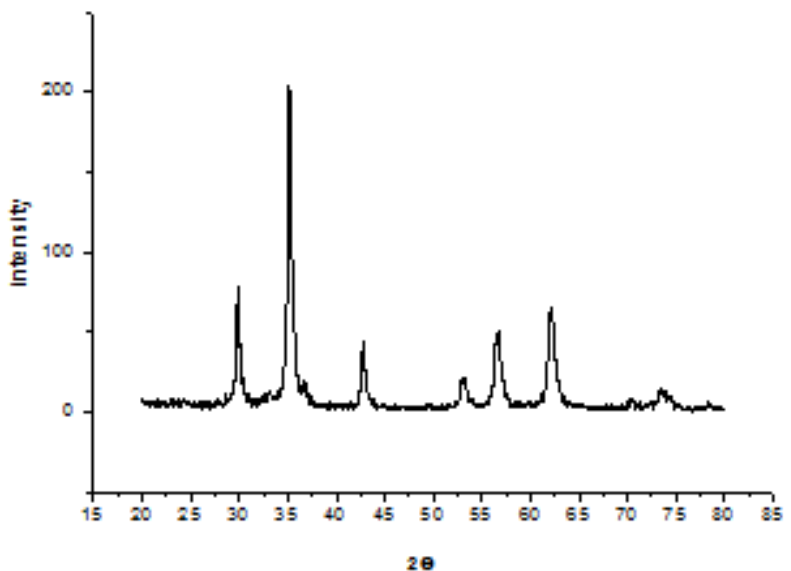

(a)

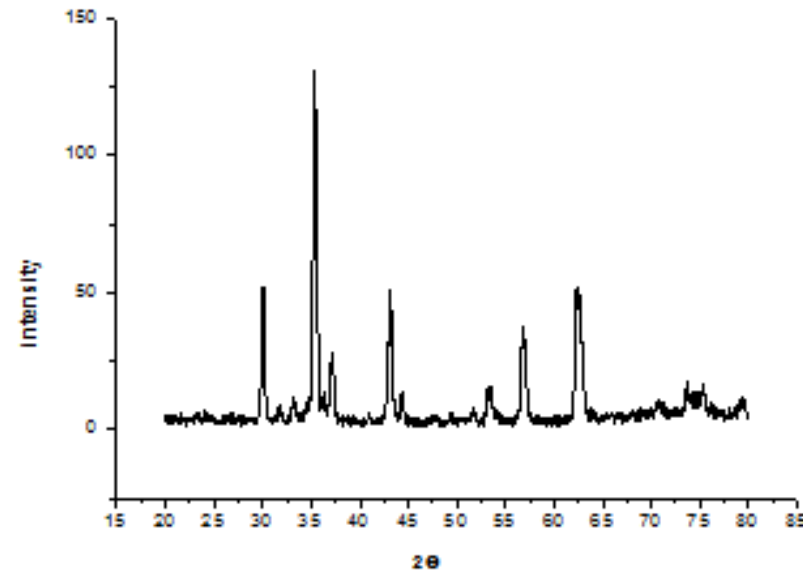

(b)

Figure 1 (a) \& (b): X-ray diffraction patterns of samples $\mathrm{Mn}_{0.6} \mathrm{Zn}_{0.4} \mathrm{Fe}_{2} \mathrm{O}_{4}$

Fig.1 (a) and (b) shows the X-ray diffraction patterns of samples $\mathrm{Mn}_{0.6} \mathrm{Zn}_{0.4} \mathrm{Fe}_{2} \mathrm{O}_{4}$ nanoparticles prepared by the two methods. All the peaks correspond to cubic spinel ferrite structure for both the samples and confirm the formation of single phase ferrite.

The values for lattice constants were calculated for $\mathrm{Mn}_{0.6} \mathrm{Zn}_{0.4} \mathrm{Fe}_{2} \mathrm{O}_{4}$ nanoparticles using the characteristic (311) peak from XRD pattern for both methods. The values of lattice constants are $8.446 \mathrm{~A}^{0}$ for oxide method and $8.495 \mathrm{~A}^{0}$ for chemical method. The lattice constant, ' $a$ ' is found to be lower for samples prepared by oxide material as compared to wet chemical method which may be attributed to the downsizing of oxide particles metals during the ball milling process, which may be responsible for the smaller crystal formation even with auto combustion producing lot of heat due to exothermic reaction, where as in the case of wet chemical method it will depend on the ions for absorption of energy available during the combustion reaction for the growth of the crystallite.

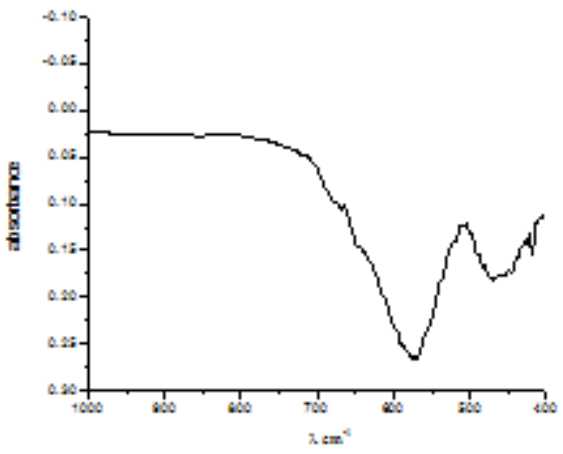

(a)

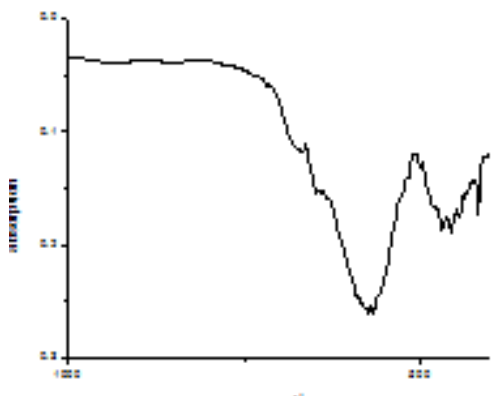

(b)

Figure 2 (a) \& (b): IR Spectra of samples $\mathrm{Mn}_{0.6} \mathrm{Zn}_{0.4} \mathrm{Fe}_{2} \mathrm{O}_{4}$

IR Spectroscopy allows us to identify the spinal structure. The three typical vibrational bonds associated with spinal structure are at (1) $600-550 \mathrm{~cm}^{-1}$ (2) $450-385 \mathrm{~cm}^{-1}$ (3) 350 $330 \mathrm{~cm}^{-1}$ for metal oxygen bonds

The IR spectrum of each sample shows two peaks, one in the range $600-550 \mathrm{~cm}^{-1}$ and the other $450-385 \mathrm{~cm}^{-1}$ corresponding to:

(1) $\mathrm{Me}_{\mathrm{T}}-\mathrm{O}-\mathrm{Me}_{\mathrm{O}}$ stretching vibration $600-550 \mathrm{~cm}^{-1}$ (2) $\mathrm{Me}_{\mathrm{O}}$ $\leftrightarrow$ O stretching vibration $450-385 \mathrm{~cm}^{-1}$

Here $\mathrm{O}$ is oxygen, $\mathrm{Me}_{\mathrm{O}}$ is metal in the octahedral site and $\mathrm{Me}_{\mathrm{T}}$ in the tetrahedral site. The metal oxygen absorption band (1) and (2) are pronounced for all spinel structures and essentially for ferrites, which are also seen in the samples. For $\mathrm{Mn}_{0.6} \mathrm{Zn}_{0.4} \mathrm{Fe}_{2} \mathrm{O}_{4}$ sample synthesized by oxide method two bands are at $569 \mathrm{~cm}^{-1}$ and $471 \mathrm{~cm}^{-1}$ and for the sample synthesized by wet chemical method two bands are at $\mathbf{5 7 4}$ $\mathrm{cm}^{-1}$ and $457 \mathrm{~cm}^{-1}$. IR spectral data of both the ferrite samples are in agreement with the reported value. [15]

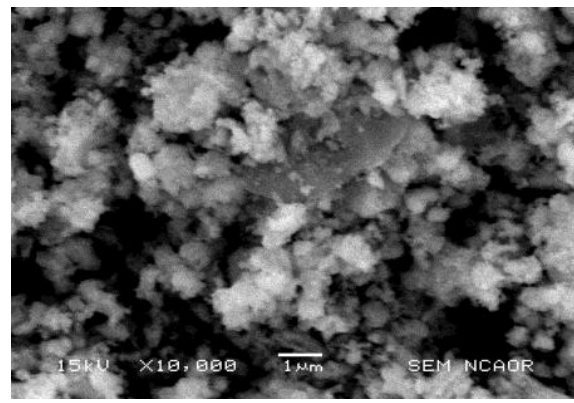

(a) 


\section{International Journal of Science and Research (IJSR) \\ ISSN (Online): 2319-7064}

Index Copernicus Value (2013): 6.14 | Impact Factor (2014): 5.611

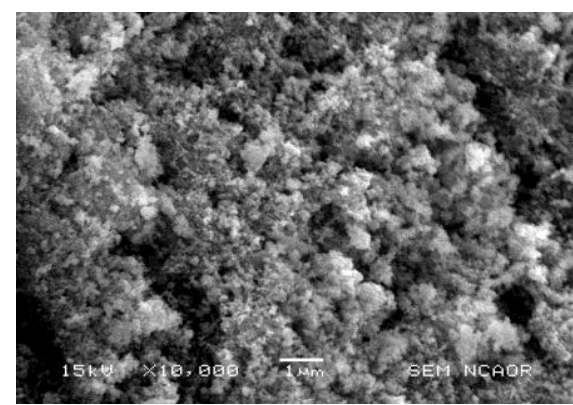

(b)

Figure 3: SEM micrograph of samples $\mathrm{Mn}_{0.6} \mathrm{Zn}_{0.4} \mathrm{Fe}_{2} \mathrm{O}_{4}$ by using (a) oxide \& (b) wet chemical method

Average crystallite sizes were calculated by using XRD data by measuring the full-width at half maximum (FWHM) for most intense characteristic (311) peak for both the samples with the help of the Scherer formula. The crystallite sizes are 24 and $43 \mathrm{~nm}$ respectively. It is found that crystallite size of the ferrite sample prepared by oxide method is lower than that for wet chemical method; it may be due to the lower values of lattice constant, due to the ball milling effect on the material size. This is also confirmed by the SEM images shown in figure 3(a) and (b) where it can be seen that particles are smaller and loosely held in the case of ferrites prepared by oxide method (fig. 3 (a)) on other hand wet chemical method gives bigger particles with higher porosity and are agglomerated (fig.3 (b)) due to higher magnetic interaction

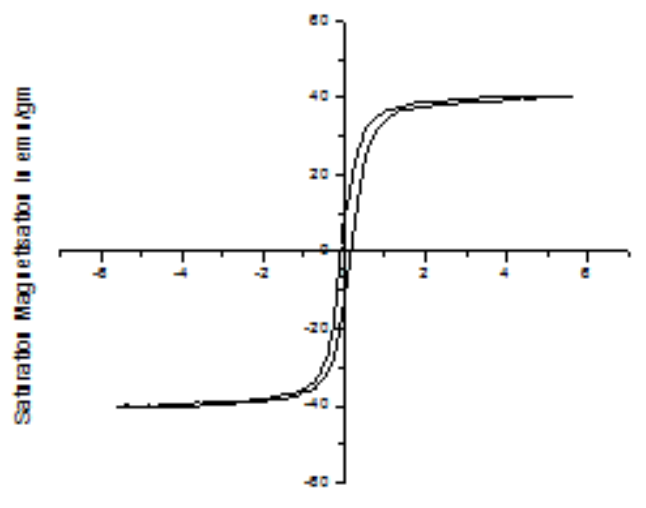

(a)

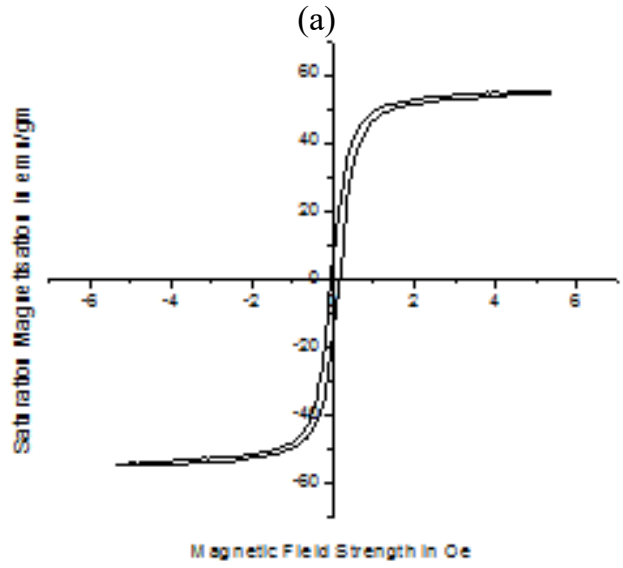

(b)

Figure 4: Saturation Magnetization of samples $\mathrm{Mn}_{0.6} \mathrm{Zn}_{0.4} \mathrm{Fe}_{2} \mathrm{O}_{4}$ (a) oxide \& (b) wet chemical method

Magnetization measurements were carried out at room temperature with a maximum applied magnetic field of 5
kOe. An analysis of the two curves indicates that the ferrite powder synthesized with oxides is found to have a lower value of saturation magnetization of $39.6 \mathrm{emu} / \mathrm{g}$ whereas for the sample synthesized with wet chemical method it is found to be $53.4 \mathrm{emu} / \mathrm{g}$. The main reason for this difference may be attributed to the particle size of the ferrites, synthesized with oxides with lower particle size and from metal salts having larger particles, similar observation are made by Costa et al in preparation of $\mathrm{Mn}-\mathrm{Zn}$ ferrite by using urea and glycine as the fuels [16]. It is well known that nano sized particles have small domain areas whose boundaries or domain walls prevent their rotation and/or spin, contributing to reduce their magnetization. Thus, in this work, the powder particles synthesized with wet chemical method were larger than those synthesized with oxides, which may be contributing directly to increase in magnetization due to their larger domain area. Therefore, the larger particle size of the $\mathrm{Mn} \mathrm{Zn}$ ferrite powders synthesized by wet chemical method shows the higher saturation magnetization values of $53.4 \mathrm{emu} / \mathrm{g}$ compared to the ferrites prepared by oxide method of $39.6 \mathrm{emu} / \mathrm{g}$.

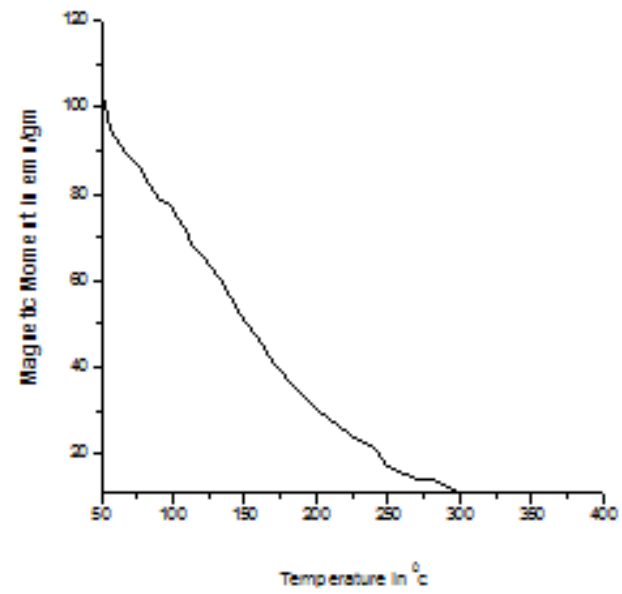

(a)

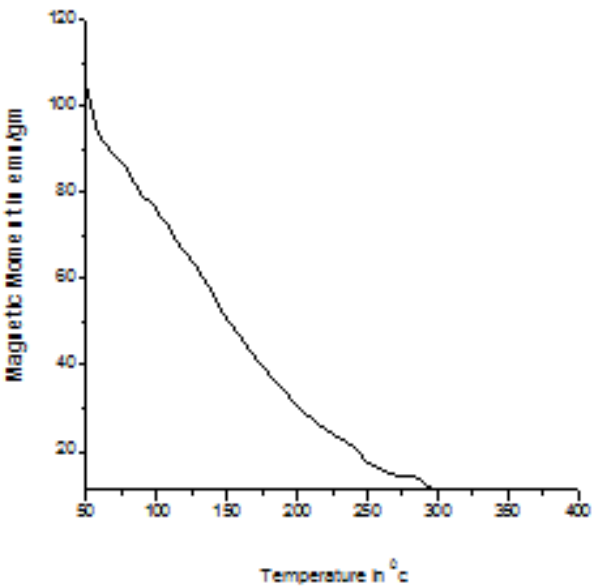

(b)

Figure 5: Curie Temperature of samples $\mathrm{Mn}_{0.6} \mathrm{Zn}_{0.4} \mathrm{Fe}_{2} \mathrm{O}_{4}$ (a) oxide \& (b) wet chemical method

The variation of the Curie temperature for $\mathrm{Mn}_{0.6} \mathrm{Zn}_{0.4} \mathrm{Fe}_{2} \mathrm{O}_{4}$ for the two methods are shown in fig 4 (a) and (b). The value of $\mathrm{Tc}$ is found to be higher in the case of the ultrafine powder than that in bulk ferrites. This is due to the deviation of cation distribution in a nano-sized particle as in comparison with its bulk counterparts as reported [17]. But ferrite prepared with wet chemical method is found to show 


\section{International Journal of Science and Research (IJSR) \\ ISSN (Online): 2319-7064 \\ Index Copernicus Value (2013): 6.14 | Impact Factor (2014): 5.611}

a marginally higher value of Curie temperature than that of the ferrite samples prepared by oxide method. In general, magnetic properties are controlled by exchange interaction of the metallic ions on the two interactive sub-lattices $\mathrm{A}$ and $B$. The change in $T_{C}$ may be positive or negative depending on the boundaries, the geometry, and the interaction. It is also possible that Tc decreases due to some unknown surface effect. For small particles a significant fraction of atoms are on the surface, and it is reasonable to expect their magnetic interactions to be different. As such, a different average Curie temperature [18] is observed.

\section{Conclusions}

Auto combustion reaction synthesis using two different starting materials solid oxides and metal salts solution with hydrazine oxalate based precursor gives the formation of monophasic crystalline $\mathrm{Mn}_{06} \mathrm{Zn}_{0.4} \mathrm{Fe}_{2} \mathrm{O}_{4}$ ferrites. The average crystallite size of the powders synthesized with oxides and metal salts were 24 and $43 \mathrm{~nm}$, respectively. SEM micrograph confirmed the formation of nano particles with higher porosity for oxides and agglomeration of ferrites from metal salts. The saturation magnetization and Curie temperature was found to be higher for ferrites synthesized with metal salts.

\section{References}

[1] P. Hu, D. Pan, S. Zhang, J. Tian, A. A. Volinsky, Mn$\mathrm{Zn}$ soft magnetic ferrite nanoparticles synthesized from spent alkaline $\mathrm{Zn}-\mathrm{Mn}$ batteries, J. Alloys Compd 509 (2011) 3991-3994.

[2] Q. Tang, D. Zhang, X. Cong, M. Wan, L. Jin, Using thermal energy produced by irradiation of $\mathrm{Mn} \mathrm{Zn}$ ferrite magnetic nanoparticles (MZF- NPs) for heat inducible gene expression, Biomaterials 29 (2008) 2673-2679.

[3] S. Noh, W. Na, et al., Nano Lett.12 (2012) 3716-3721.

[4] I. Sharifi, H. Shokrollahi, S. Amiri, J.Magn.Magn.Mater.324 (2012) 903-915.

[5] A. Goldman, Modern Ferrite Technology, second ed., Springer, Pittsburgh, 2006.

[6] J. Topfer, A. Angermann, Mater. Chem. Phys. 129 (2011) 337-342.

[7] R. Justin Joseyphus, A. Narayanasamy, K. Shinoda, B. Jeyadevan, K. Tohji, J. Phys. Chem. Solids 67 (2006) 1510-1517.

[8] J. Giri, T. Srihasha, S. Asthana, T. K. Gundu Rao, A. K. Nigam, D. Bahadur, J. Magn. Magn. Mater. 293 (2005) $55-61$.

[9] S. Tao, A. Borrasso, B. Liu, V. Dravid, J. Am. Ceram.Soc.94 (5) (2011) 1490-1495.

[10] M. Sivakumar, A. Towata, K. Yasui, T. Tuziuti, T. Kozuka, Y. Iida, M. M. Maiorov, E. Blums, D. Bhattacharya, N. Sivakumar, M. Ashok, Ultrason. Sono chem.19(3)(2012)652-658.

[11]C. Venkataraju, G. Sathishkumar, K. Sivakumar, J.Magn.Magn. Mater. 322 (2010) 230-233.

[12]A. Thakur, M. Singh, Preparation and characterization of nanosize $\mathrm{Mn}_{0.4} \mathrm{Zn}_{0.6} \mathrm{Fe}_{2} \mathrm{O}_{4}$ ferrite by citrate precursor method, Ceram. Int. 29 (2003) 505-511.

[13] K. Praveena, K. Sadhana, S. R. Murthy, Mater.Res.Bull.47 (4) (2012) 1096-1103.
[14] P. P. Hankare, R. P. Patil, U. B. Sankpal, S.D. Jadhav, K. M. Garadkar, S. N. Achary, Synthesis and morphological study of chromium substituted $\mathrm{Zn}-\mathrm{Mn}$ ferrites nanostructures via sol-gel method, J. Alloys Compd. 509 (2011) 276-280.

[15] R. Iyer, R. Desai, R. V. Upadhyay, Bull. Mater. Sci., 32 2, ( 2009) pp. 141-147.

[16] A.C.F.M. Costa, V.J. Silva, C.C. Xin, D.A. Vieira, D.R. Cornejo, R.H.G.A. Kiminami, J . Alloys and Compounds 495 (2010) 503-505.

[17] C. Rath, S. Anand, R. P. Das, J. App. Phys. 91(2002) 2211.

[18] J. P. Chen, C. M. Sorenson, K. J. Klabunde, G. G. Hadjipanayis, E. Delvin, A. Kostidas, Phys. Rev. B54 (1996) 9288. 